\title{
ULTRASTRUCTURAL STUDY OF THE EFFECT OF ZINC OXIDE NANOPARTICLES ON RAT PAROTID SALIVARY GLANDS AND THE PROTECTIVE ROLE OF QUERCETIN
}

\author{
Sara A. Hamza ${ }^{l} M S C$, Hanaa M. Aly $P h D$, Samia O. Soliman ${ }^{2} P h D$, Dina M. Abdallah ${ }^{3} P h D$
}

\begin{abstract}
INTRODUCTION: Nanotechnology is the technology of diagnosing, treating, and preventing diseases using nanoscale structured materials. Zinc oxide nanoparticles (ZnO NPs) have useful effects for their less environmental hazards and for their application usages: tooth pastes, biomedicine and food as zinc supplements. On the other hand, ZnO NPs have toxic effect due to their tissue accumulation ability. Quercetin (Qc) is an antioxidant, categorized as a flavonol. Its beneficial effects are attributed to its phenolic hydroxyl groups. It has antioxidant and antiinflammatory activities.

OBJECTIVES: To evaluate the effect of ZnO NPs on rat parotid salivary glands and to investigate the possible protective role of Qc.

MATERIALS AND METHODS: Twenty-four adult male albino rats were divided into three equal groups: group (I) control, group (II) received ZnO NPs $300 \mathrm{mg} / \mathrm{kg}$ and group (III) received ZnO NPs $300 \mathrm{mg} / \mathrm{kg}+$ Qc $200 \mathrm{mg} / \mathrm{kg}$ for 28 days. At the end of the experiment, animals were euthanized and the parotid glands were dissected out. The effect of ZnO NPs on the parotid glands as well as the protective role of Qc were assessed by transmission electron microscopy.

RESULTS: In group(II) the acinar cells showed signs of toxicity as apoptotic nuclei, degenerated mitochondria, dilated rough endoplasmic reticulum and vacuolization in the cytoplasm. Group (III) parotid glands exhibited remarkable improvement in the ultrastructure of their acinar cells and duct system. This appearance was near to that of control group.

CONCLUSIONS: The study proved ZnO NPs toxicity and revealed that oral administration of Qc effectively prevented the toxicity associated with ZnO NPs administration in rat models. Thus, Qc might be used as a prophylactic treatment to prevent ZnO NPs toxicity.

KEYWORDS: Zinc Oxide Nanoparticles, Quercetin, Parotid Salivary Glands.
\end{abstract}

1- Assistant lecturer of Oral Biology - Faculty of Dentistry - Alexandria University
2- Professor of Oral Biology - Faculty of Dentistry - Alexandria University.
3-

\section{INTRODUCTION}

The rapid growth of nanotechnology and the increased production, consumption and disposal of many engineered nanoparticles (ENPs), created an increasing concern that human exposure to them - accidentally or incidentally - can lead to significant adverse health effects, especially that the study of their toxicological effects has lagged behind the speed of their mass production (1).

Zinc oxide $(\mathrm{ZnO})$ is an inorganic compound, that is widely used in the everyday applications. In 2013 it was listed as a Generally Recognized as Safe material (GRAS) by the Food and Drug Administration agency, and it is currently used as a food additive (2).

Zinc oxide nanoparticles ( $\mathrm{ZnO}$ NPs) are one of the most important ENPs, whose production is increasing every year. They are utilized in diverse industrial fields such as dyes, paints, pigments, tooth pastes, rubber, cigarettes, ceramics, chemical fibers, electronics, catalysts, antibiotics, medical diagnosis, sunscreens, cosmetics, food products as breakfast cereals and personal care products (3).

It has been reported that $\mathrm{ZnO}$ in the nanoscale has antimicrobial, antifungal and anticorrosive properties and potential application in food preservation, thus they are incorporated in polymeric matrices to provide antimicrobial activity (4).

However, it is controversial whether ZnO NPs are safe or hazardous. Some studies considered that generally, $\mathrm{Zn}$ is a material with low toxicity, as it is an essential trace element in the human body and is commonly added as a nutritional supplement (5). On the other hand, others demonstrated the hazardous effect of $\mathrm{ZnO}$ NPs in the form of cytotoxicity and genotoxicity in cultured human cells and experimental animals (6). Thus, Nanoparticle Technology is a doubleedged sword on living cells (7).

The primary means by which inadvertent nanoparticle exposure in humans can occur is via inhalation, ingestion, or dermal contact. After gaining access to the circulatory system, nanoparticles can be distributed throughout the body and to specific organs (8), and taken up by cells through phagocytic or endocytic mechanisms (9).

The mechanisms of cytotoxicity from $\mathrm{ZnO}$ nanoparticles are not completely understood. However, oxidative stress is thought to be the key mechanism responsible for $\mathrm{ZnO}$ adverse effects, as it induces production of reactive oxygen species (ROS) and other oxidative agents (10). If ROS production exceeds the antioxidative defensive capacity of the cell, it results in oxidative damage of biomolecules which can lead to cell death and apoptosis (11).

The liver, heart, spleen, pancreas, bone and salivary glands all appear to be targeted sites of $\mathrm{ZnO}$ nanoparticles (12).

Quercetin (3, 3\, 4\, 5, 7- pentahydroxyflavone) is an antioxidant, that is categorized as a flavonol; one of the six subclasses of flavonoid compounds. It is the most abundant flavonoid molecule, that is widely distributed in the plant kingdom. They are found in a variety of foods including apples, berries, brassica vegetables, grapes, onions, shallots, 
tea and tomatoes, as well as many seeds, nuts, flowers, barks and leaves (13).

The beneficial effects of quercetin are primarily attributed to its phenolic hydroxyl groups. It has antioxidant and anti - inflammatory activities (14).

Thus the aim of this study was to evaluate the effect of $\mathrm{ZnO}$ NPs on the rat parotid salivary glands and to investigate the possible protective role of Qc.

\section{MATERIALS AND METHODS}

Twenty-four male albino rats weighing about 150-200 grams and their age ranged from 3-6 months were used in this study. The guidelines for the care and use of experimental animals were followed according to the Institute of Medical Research, Alexandria University from where the animals were obtained and the work was done. Rats were randomly divided into 3 equal groups 8 rats each. Group (I): rats were used as controls, and received daily $10 \mathrm{ml} / \mathrm{kg}$ distilled water (15) orally for 28 days (16).

Group (II): rats were treated with daily oral administration of $300 \mathrm{mg} / \mathrm{kg}$ body weight Zinc oxide nanoparticles (Sigma - Aldrich Chemical Company (St. Louis, MO, USA) for 28 days (16).

Group (III): rats were treated with daily oral administration of $300 \mathrm{mg} / \mathrm{kg}$ body weight Zinc oxide nanoparticles and simultaneously received oral Quercetin (Nanotech - Egypt Chemical Company) at a dose of 200 $\mathrm{mg} / \mathrm{kg} /$ day (17) for 28 days (16).

The dose volume of the distilled water, was maintained for both $\mathrm{ZnO}$ NPs and Quercetin, and was $10 \mathrm{ml} / \mathrm{kg} /$ day, $(14,15)$. Animals were clinically evaluated every week for general health, activity and body weight throughout the experimental period. One day after the last administration, the animals of each group were euthanized, and the right and left parotid salivary glands were dissected out and immersed in $2.5 \%$ glutaraldehyde in phosphate buffer to be prepared for transmission electron microscopy (18).

The NPs were characterized using the transmission electron microscope (TEM) (16) \{Electron Microscopy Unit, Faculty of Science, University of Alexandria\} A small drop of the ZnO NPs' suspension was placed onto the TEM grids, coated with a thin carbon film and allowed to evaporate. Then, electron micrographs of several locations on the grid were taken. (19) The morphology and size of $\mathrm{ZnO}$ NPs in the present study showed that the individual particles had a diameter $<50 \mathrm{~nm}$. These particles were mostly spherical in shape and electron dense forming aggregates of different sizes, as shown by transmission electron micrographs (Fig.1).

\section{STATISTICAL ANALYSIS}

Statistical analysis of the body weight was done using IBM SPSS software package version 20.0. ANOVA was used for comparing the three studied groups for normally distributed quantitative variables (20).

\section{RESULTS}

\section{Effects of $\mathrm{ZnO}$ nanoparticles on body weight changes} and general health:

During the experimental period, one rat died at the second week in the $\mathrm{ZnO}$ nanoparticles-treated group and was replaced by another one. Comparing the readings of the mean body weights in grams for each group in successive four weeks showed that there was no statistically significant difference in the mean body weight between the controls and the groups receiving $\mathrm{ZnO}$ nanoparticles nor the group receiving $\mathrm{ZnO}$ nanoparticles with Quercetin (Table 1).

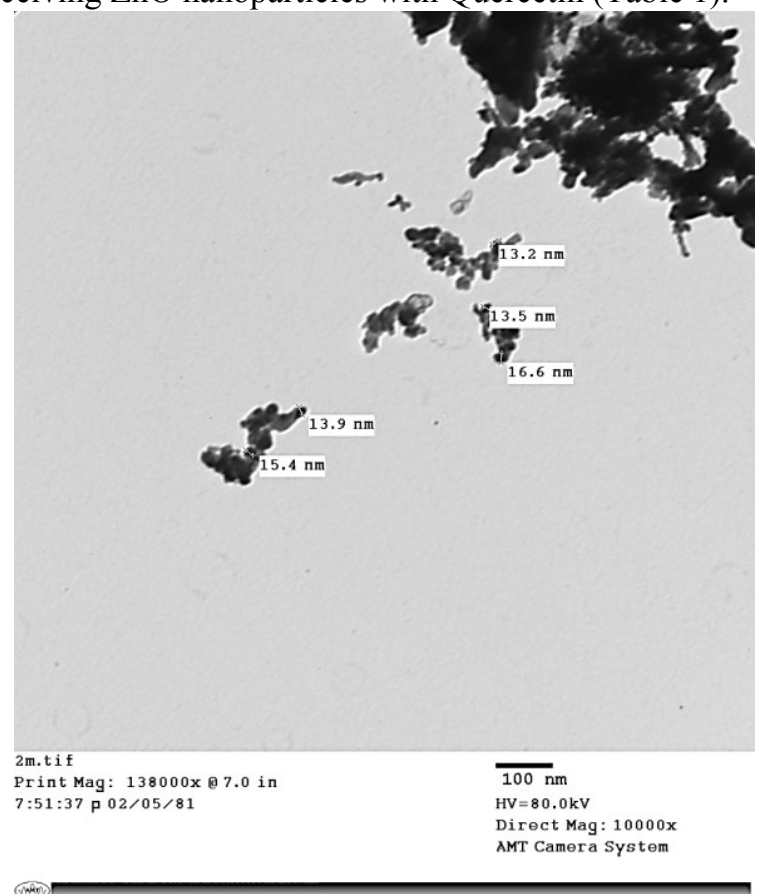

Figure (1): Transmission electron micrograph (TEM) of $\mathrm{ZnO}$ NPs' suspension showing that most of the nanoparticles are spherical in shape with diameter $<50 \mathrm{~nm}$. (X1000)

\section{Ultrastructural results:}

The observations of the transmission electron microscope of the parotid salivary glands showed differences among the different groups. However, all specimens of the same group showed similar results.

\section{Group I (control):}

The serous acinar cells of the gland showed, normal euochromatic nuclei at the base of the cell. The cytoplasm accommodated abundant amount of well-organized rough endoplasmic reticulum. Also they contained numerous well organized golgi complex, numerous mitochondrial figures and plenty spherical secretory zymogen granules with different degrees of electron density in the part of the cell adjacent to the lumen. (Fig.2).

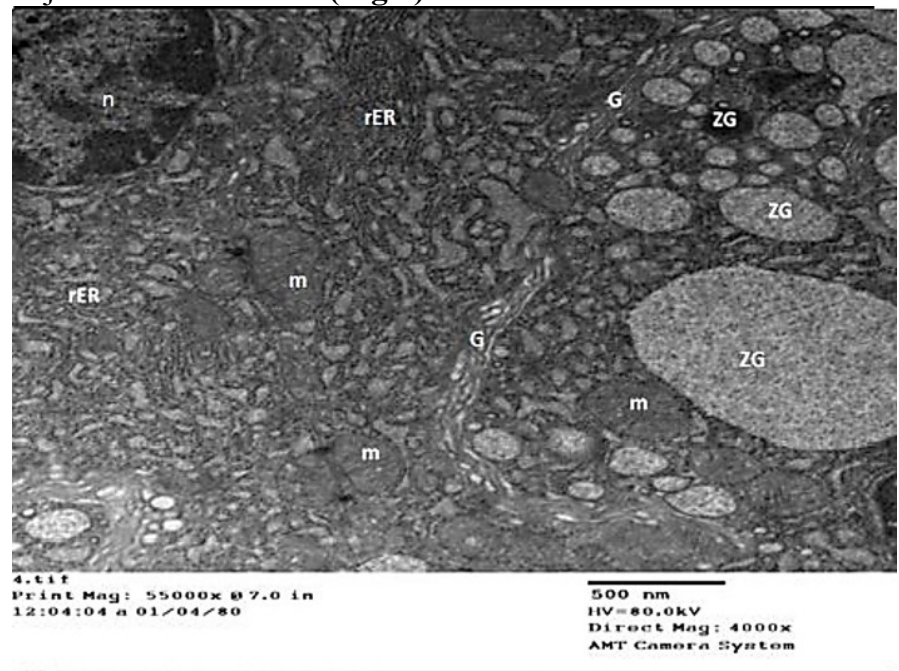

Figure (2): TEM, group (I), showing: Serous acinus with normal nucleus (n), abundant rough endoplasmic reticulum (rER), extensive well developed golgi complex $(\mathrm{G})$, numerous normal mitochondria $(\mathrm{m})$ and profound amount of spherical electron dense and electron lucent secretory zymogen granules (ZG) (X4000). 
Table (1): Comparison between the different studied groups according to mean Body weight.

\begin{tabular}{|c|c|c|c|c|}
\hline \multirow{2}{*}{$\begin{array}{l}\text { Reading per } \\
\text { week }\end{array}$} & \multicolumn{3}{|c|}{$\begin{array}{c}\text { Body weight in grams } \\
\text { Mean (SD) }\end{array}$} & \multirow{2}{*}{$\begin{array}{l}\text { ANOVA } \\
\text { P } 1\end{array}$} \\
\hline & Group I & Group II & Group III & \\
\hline $\begin{array}{l}1^{\text {st }} \text { reading } \\
\text { (at the start } \\
\text { of } \\
\text { experiment) }\end{array}$ & $\begin{array}{c}169-173 \\
170.9 \pm 1.2\end{array}$ & $\begin{array}{c}169-178 \\
171.8 \pm 3.4\end{array}$ & $\begin{array}{c}170-177 \\
173.3 \pm 2.9\end{array}$ & $\begin{array}{c}0.68 \\
0.499\end{array}$ \\
\hline $\begin{array}{l}2^{\text {nd }} \\
\text { reading(at } \\
\text { the } 1^{\text {st }} \\
\text { week) }\end{array}$ & $\begin{array}{c}173-179.0 \\
177.1 \pm 1.81\end{array}$ & $\begin{array}{c}172-180.0 \\
174.3 \pm 2.60\end{array}$ & $\begin{array}{c}170-184.0 \\
177.9 \pm 4.76\end{array}$ & $\begin{array}{l}0.74 \\
0.39\end{array}$ \\
\hline $\begin{array}{l}3^{\text {rd }} \\
\text { reading(at } \\
\text { the } 2^{\text {nd }} \\
\text { week) }\end{array}$ & $\begin{array}{c}184-193 \\
186.4 \pm 3.1\end{array}$ & $\begin{array}{c}177-200 \\
185.1 \pm 8.0\end{array}$ & $\begin{array}{c}180-200 \\
188.6 \pm 6.8\end{array}$ & $\begin{array}{l}1.01 \\
0.29\end{array}$ \\
\hline $\begin{array}{l}4^{\text {th }} \\
\text { reading(at } \\
\text { the } 3^{\text {rd }} \\
\text { week) }\end{array}$ & $\begin{array}{c}195-205 \\
199.5 \pm 3.3\end{array}$ & $\begin{array}{c}182-205 \\
191.6 \pm 7.8\end{array}$ & $\begin{array}{c}185-205 \\
193.8 \pm 6.0\end{array}$ & $\begin{array}{l}0.79 \\
0.33\end{array}$ \\
\hline $\begin{array}{l}5^{\text {th }} \text { reading } \\
\text { (at the } 4 \mathrm{rth} \\
\text { week) }\end{array}$ & $\begin{array}{c}205-227.0 \\
215.3 \pm 8.12\end{array}$ & $\begin{array}{c}190-219.0 \\
199.8 \pm 9.22\end{array}$ & $\begin{array}{c}190-219.0 \\
202.1 \pm 10.80\end{array}$ & $\begin{array}{c}1.22 \\
0.107\end{array}$ \\
\hline $\begin{array}{l}\text { ANOVA } \\
\text { P2 }\end{array}$ & $\begin{array}{c}12.05 \\
0.001^{*}\end{array}$ & $\begin{array}{c}10.3 \\
0.006^{*}\end{array}$ & $\begin{array}{c}8.96 \\
0.013^{*}\end{array}$ & \\
\hline
\end{tabular}

P1 comparison between the three groups. At the same time

P2 comparison between interval times in the same group.

\section{Group II (ZnO NPs 300 mg/kg):}

The serous acinar cells exhibited, numerous dilated rough endoplasmic reticulum, lysosomes and vacuolation of the cytoplasm. The cells also showed, apoptotic nuclei with heterogenic chromatin, and autophagocytosed mitochondria. The cytoplasm showed extensive degeneration (Fig.3). The cellular lining of the intercalated ducts exhibited degenerative changes which included altered mitochondria, vacuolization of the cytoplasm and widening of the lumen (Fig. 4).

\section{Group III (ZnO NPs 300 mg/kg with QE $200 \mathrm{mg} / \mathrm{kg}$ ):}

The cells of the serous acini showed, normal nuclei with normal figures of chromatin distribution and numerous secretory zymogen granules with intermediate degree of electron density. The cytoplasm exhibited, few vacuolization, slight dilatation of the rough endoplasmic reticulum with normal mitochondria and well developed golgi complex (Fig.5). The Intercalated duct had normal cell lining with normal euchromatic nuclei, normal electron dense secretory granules, well oriented golgi complex, well organized rough endoplasmic reticulum and narrow lumen (Fig.6

\section{DISCUSSION}

Among the numerous engineered nanoparticles (ENPs), $\mathrm{ZnO}$ ones are considered to be promising candidates for many scientific and industrial applications, due to their interesting electrical, chemical, thermal and optical properties. However, lately there has been a campaign in some countries that share in the organization for economic cooperation and development (OECD), to alert the public of $\mathrm{ZnO}$ NPs' potential toxicity. This campaign has aimed to raise the awareness about the possible hazards of these NPs, considering that they are not totally inert, and even if they were, they would not be of value in many of their current applications which rely upon a degree of their chemical reactivity. In such a context, their cytotoxicity has become one of the most significant threats that should be primarily evaluated, before extending their applications in practice (21).

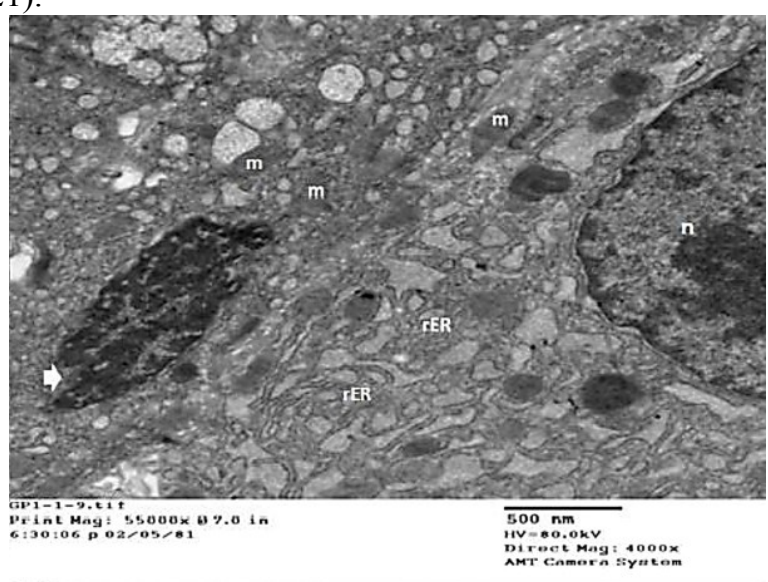

Figure (3): TEM, group (II), showing: Serous acinus with extensive and drastic changes in both of the nuclei (n) and cytoplasm accommodating apoptotic bodies (arrow), dilated rough endoplasmic reticulum (rER)and degenerated mitochondria (m) (X4000)

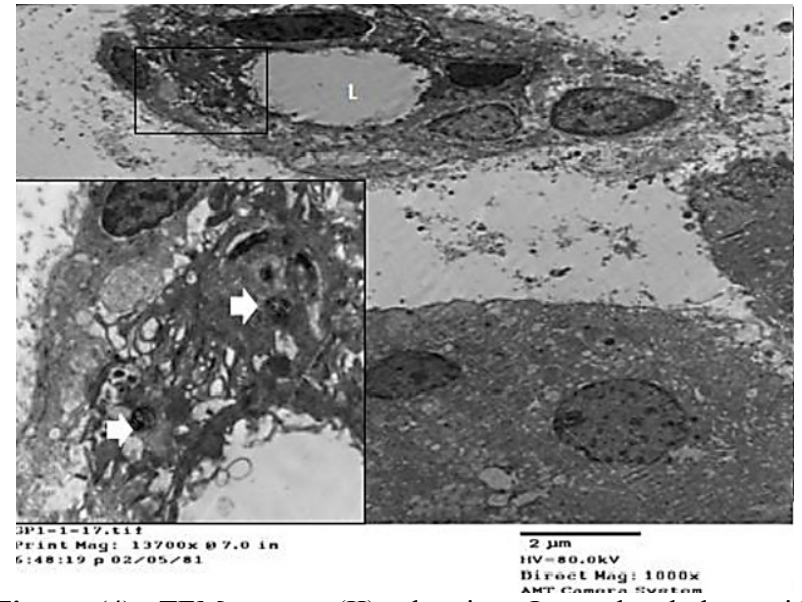

Figure (4): TEM, group (II), showing: Intercalated duct with degenerated epithelial lining, widening of the lumen (L) and electron dense nuclei (X1000). The inset reveals higher magnification of the encircled part in the previous figure illustrating an apoptotic bodies (arrow) and massive cytoplasmic changes with altered mitochondria and vacuolization of the cytoplasm (X 5000).

The human body may be exposed to ZnO NPs via several possible routes, including the ingestion, inhalation, intravenous injection and dermal penetration. However, the oral route was selected as a route of rats' exposure to $\mathrm{ZnO}$ NPs in this study, not only because the oral route follows the guidelines of the (OECD), that stated this route for testing any chemical (22), but also because humans have a higher chance of $\mathrm{ZnO}$ NPs' ingestion in the food-related products, with a potential for exposure to higher doses with the frequent ingestion (23).

Regarding the dose of $\mathrm{ZnO}$ NPs used in the present study, we chose to work with a dose ( $300 \mathrm{mg} / \mathrm{kg}$ body weight/day) that is agreed by the OECD guidelines for investigating a new chemical substance (23). Zinc oxide nanoparticles used in this study were well ultra-sonicated, just before their administration to the experimental animals, due to the fact that they could not remain stable in suspensions and they 
are rapidly ready to form small aggregates, as a result of their nano-hydrodynamic size. It is known that ultrasonication is the most effective way for disaggregating NPs in water (24).

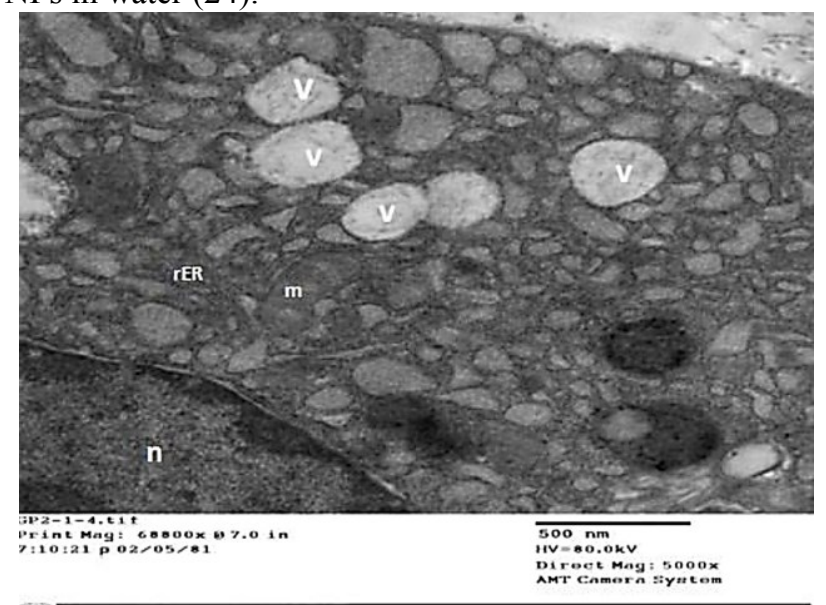

Figure (5): TEM, group (III), showing: Serous acinus with normal nucleus (n), slight dilatation of the rough endoplasmic reticulum (rER), normal mitochondria $(\mathrm{m})$ and few vacuolation of the cytoplasm (v) (X5000).

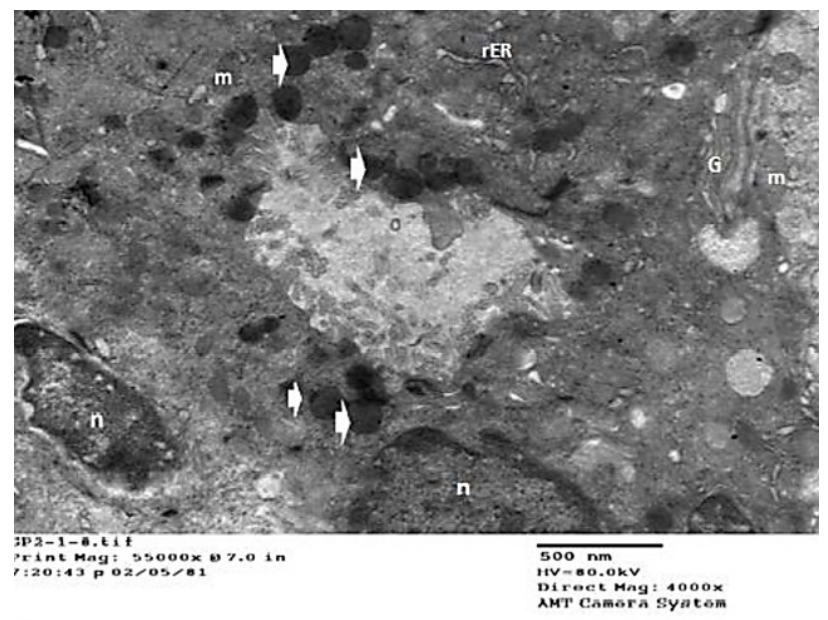

Figure (6): TEM, group (III), showing: Parts of the intercalated duct cells adjacent to its lumen and revealing restoration of the ultrastructural details of the cells including normal euchromatic nucleus (n), normal electron dense secretory granules (arrows), well developed golgi complex $(\mathrm{G})$, normal mitochondria $(\mathrm{m})$ and well organized rough endoplasmic reticulum (rER) (X4000).

The duration of 28 days was chosen according to Chung et al. (25) who evaluated $\mathrm{Zn}+2$ ions concentration in plasma using an inductively coupled plasma-atomic emission spectroscopy (ICP-AES) after daily oral administration of both 250 and $500 \mathrm{mg} / \mathrm{kg}$ body weight, doses. They demonstrated that $\mathrm{ZnO}$ NPs resulted in a statistically increased plasma zinc level with a subsequent accumulation in the blood circulation and deposition in the different organs, after a period of 28 days.

In the present study, electron microscopic examination of the parotid glands in group II, demonstrated that $\mathrm{ZnO}$ NPs have a potential to induce cytotoxic effects on the acinar cells as well as the duct system.

These were revealed by the variable degrees of degenerative changes involving most of the cells. The acinar cells showed, apoptotic nuclei with heterogenic chromatin, as well as autophagocytosed mitochondria and numerous dilated rough endoplasmic reticulum. The cytoplasm showed extensive degeneration and contained many disorganized figures of golgi complex. The intercalated ducts had degenerated epithelial lining with altered mitochondria, vacuolization of the cytoplasm and widening of the lumen. These ultrastructural changes were also observed in studies of submandibular salivary glands of rats intoxicated with $\mathrm{ZnO}$ NPs (26).

$\mathrm{ZnO}$ NPs could affect acinar cells through different mechanisms, which provide various postulations to interpret the ultrastructural changes encountered in the present study.

One important mechanism of $\mathrm{ZnO}$ NPs' toxicity is the particle's dissolution in the biological environments. This dissolution or ionization not only increases under the acidic conditions, but also in the presence of biological components such as amino acids and peptides (27). Müller et al. (28) suggested that intracellular release of ionic $\mathrm{Zn}+2$ from the particles with a subsequent elevation of the cytosolic $\mathrm{Zn} 2+$ concentration, is the original factor responsible for cell membrane injuries, triggering inflammatory responses, DNA damage and death of the mammalian cells.

Such a concept has been supported by the study of Kao et al. (29) They demonstrated that ZnO NPs after being enodocytosed by cells via endocytotic vesicels, they fuse with the endosomes that provide a medium of a low $\mathrm{pH}$ (about 5.5), that is quite favorable for dissolution of $\mathrm{Zn} 2+$ ions. This is followed by their leakage from the endosomes with elevation of the cytosolic $\mathrm{Zn} 2+$ concentration. In a further step and as a trial from the mitochondria to maintain cytosolic Zn2+ homeostasis, mitochondria sequester Zn2+ ions. Increased mitochondrial $\mathrm{Zn} 2+$ concentration, could inhibit the cellular and also affects the mitochondrial membrane permeability and opens mitochondrial pores that release factors that may trigger the intrinsic pathway of apoptosis.

Such explanation comes in agreement with some ultrastructural changes encountered in the present study that revealed apoptotic changes at the ultrastructural level as, the apoptotic nuclei and autophagocytosed mitochondria of acinar cells. Another possible explanation for $\mathrm{ZnO}$ NPs' toxicity might be the oxidative effect of the nano-class materials, that is followed by inability of the cells to deal with the residues that resulted from the metabolic and structural disturbances. The theme of particle-induced oxidative injury has become an established general mechanism for NPs' toxicity (23).

Oxidative stress leads to accumulation of reactive oxygen species (ROS), even when only small amounts of ZnO NPs are incorporated into the cells. ROS attack the DNA, generating a huge range of base and sugar modifications and a number of alterations, such as DNA cleavage, DNAprotein cross links and oxidation of purines. Induction of ROS can occur spontaneously once ZnO NPs are exposed to the acidic medium of lysosomes owing to their chemical and surface nano-level characteristics. Moreover, can occur after their interaction with the oxidative organelles, such as the mitochondria or after their direct interaction with proteins, lipids, nucleic acids, sugars and enzymes due to their small size and large specific surface area, giving them a state of high reactivity. These interactions interfere with the biological system's ability to detoxify the reactive intermediates or to repair the resulting damage, (30) the issue that may explain the encountered cytoplasmic 
degeneration and nuclear changes observed in the acinar cells of this study.

Vacuolar appearance of rat acinar cells was observed in the electron microscopic examination of the treated group. These findings were also detected within the cytoplasm of germ cells and olfactory epithelial cells exposed to $\mathrm{ZnO}$ NPs $(31,32)$. These vacuoles reflect cellular swelling, that may be attributed to failure of the energy-dependent $\mathrm{Na}+-$ $\mathrm{K}+$ ion pumps in the plasma membranes, due to lipid peroxidation, leading to an intracellular accumulation of $\mathrm{Na}+$ and progressive osmolarity changes, with a consequent entry of water into the cells (33).

On the other hand, in the present work, the electron microscopic examinations of the acinar cells and duct system of group III rats who received $\mathrm{ZnO}$ NPs and quercetin during the experimental period, showed almost a similar ultrastructural appearance as the control rats of group I. This result ensured the safety of using quercetin as an antioxidant protective agent and showed evident improvement, as observed at the ultrastructural level. This group revealed preserved cytoplasmic organelles and almost normal chromatin patterns, but with minimal cytoplasmic vacuoles .

As mentioned before, there is a substantial evidence supporting the role of ROS as a major mechanism explaining the toxic effects of ZnONPs $(23,37)$. That is why the role of antioxidants as protective agents against ROS induced changes, has been considered in the present study .

Quercetin (Qc) is a flavonol, that is widely distributed in the plant kingdom. It has various important properties, making it suitable to act as antioxidant (34), antitoxin (35) and anti-inflammatory agent (36). It can scavenge free radicals, inactivate ROS and chelate pro-oxidant transition metals, preventing oxidation of membrane lipids, oxidative modification of proteins and DNA fragmentation (37). An extensive number of recent animal researches has been focused on these antioxidant and cyto-protective potentials of Qc $(38,39,40)$.

In addition, Qc prevents the free radicals from activation of the transcription factors of the pro-inflammatory cytokines. It also suppresses the over-expression of the inducible form of nitric oxide synthase enzyme (iNOS), which is induced by various inflammatory stimuli (34).

\section{CONCLUSIONS}

The findings of this study proved the toxicity of $\mathrm{ZnO}$ NPs, when administered orally, and declared the protective role of Quercetin in preventing this toxilogical effect. So, Quercetin can be used as a prophylactic treatment to avoid ZnO NPs hazards.

\section{CONFLICT OF INTEREST}

The authors declare that they have no conflict of interest.

\section{REFERENCES}

1. Biskos G, Schmidt-Ott A. Airborne engineered nanoparticles: potential risks and monitoring challenges for assessing their impacts on children. Pediatric Respir. Rev. 2012; 13:79-83.

2. Espitia P, Soares N, Coimbra J, José de Andrade N, Cruz R, Medeiros E. Zinc Oxide Nanoparticles: Synthesis, Antimicrobial Activity and Food Packaging Applications. Food Bioprocess Technol. 2012; 5:1447-64.
3. Baek M, Chung HE, Yu J, Lee JA, Kim TH, Oh JM, et al. Pharmacokinetics, tissue distribution, and excretion of zinc oxide nanoparticles. International Journal of Nanomedecine. 2012; 7:3081-97.

4. Niu, L.N., Fang M, Jiao K, Tang LH, Xiao YH, et al. Tetrapod-like zinc oxide whisker enhancement of resin composite. J Dent Res. 2010; 89:746-50.

5. De Sá JS, Moreira DC, Louvera Silva KA, Morgano MA, Quintaes KD. Consumption of oral hospital diets and percent adequacy of minerals in oncology patients as an indicative for the use of oral supplements. Clin. Nutr. 2014;33:655-61 .

6. Guan R, Kang T, Lu F, Zhang Z, Shen H, Liu M. Cytotoxicity, oxidative stress, and genotoxicity in human hepatocyte and embryonic kidney cells exposed to $\mathrm{ZnO}$ nanoparticles. Nanoscale Res Lett. 2012; 7:602.

7. Jennifer M, Maciej W. Nanoparticle Technology as a Double-Edged Sword: Cytotoxic, Genotoxic and Epigenetic Effects on Living Cells. Journal of Biomaterials and Nano biotechnology. 2013; 4:53-63

8. Hagens WI, Oomen AG, De Jong WH, Cassee FR, Sips AJ. What do we (need to) know about the kinetic properties of nanoparticles in the body? Regul Toxicol Pharmacol. 2007; 49:217-29.

9. Lanone S, Boczkowski J. Biomedical applications and potential health risks of nanomaterials: molecular mechanisms. Curr Mol Med. 2006; 6:651-63.

10. Vandebriel RJ, De Jong WH. A review of mammalian toxicity of $\mathrm{ZnO}$ nanoparticles. Nanotechnol. Sci. and Appl. 2012; 5:61-71.

11. Ryter SW, Kim HP, Hoetzel A, Park JW, Nakahira K, Wang $\mathrm{X}$, et al. Mechanisms of cell death in oxidative stress. Antioxid Redox Signal. 2007; 9:49-89.

12. Wang B, Feng W, Wang M, Wang TC, Gu Y, Motao Z, et al. Acute toxicological impact of nano- and submicro-scaled zinc oxide powder on healthy adult mice. J Nanopart Res. 2008; 10:263-76.

13. Kelly G. Quercetin Monograph. Alternative Medicine Review. 2011; 16:172-3.

14. Verma R, Kushwah L, Gohel D, Patel M, Marvania T, Balakrishnan S. Evaluating the Ameliorative Potential of Quercetin against the Bleomycin-Induced Pulmonary Fibrosis in Wistar Rats. Pulmonary Medicine. 2013; 2013:10.

15. Pasupuleti S, Alapati S, Ganapathy S, Anumolu G, Pully NR, Prakhya BM. Toxicity of zinc oxide nanoparticles through oral route. Toxicol Ind Health. 2012; 28:675-86.

16. Chung H E J, Baek Yu M, Lee J A, Kim M S, Kim S H, Maeng E H, et al. Pharmacokinetics, tissue distribution, and excretion of zinc oxide nanoparticles. Int J Nanomedicine. 2012; 7:3081-97.

17. Faddah LM, Abdel Baky NA, Al-Rasheed NM, Fatani AJ, Atteya M. Role of quercetin and arginine in ameliorating nano zinc oxide-induced nephrotoxicity in rats. BMC Complement Altern Med. 2012; 12:60.

18. Fawcett DW. Bloom and Fawcett: A Textbook of Histology. 12 $2^{\text {th }}$ ed. New York: Chapman and Hall; 1998:769-804.

19. Cormack DH. Essential Histology. Philadelphia: Lippincott Williams \& Wilkins; 2001.

20. Kirkpatrick LA, Feeney BC. A simple guide to IBM SPSS statistics for version 20.0. Student ed. Belmont, Calif.: Wadsworth, Cengage Learning; 2013. 
21. Moezzi A, McDonagh AM, Cortie MB. Zinc oxide particles: synthesis, properties and applications. Chem Eng J. 2012; 185:1-22.

22. Pasupuleti S, Alapati S, Ganapathy S, Anumolu G, Pully NR, Prakhya BM. Toxicity of zinc oxide nanoparticles through oral route. Toxicol Ind Health. 2012; 28:675-86.

23. Sharma V, Singh P, Pandey AK, Dhawan A. Induction of oxidative stress, DNA damage and apoptosis in mouse liver after sub-acute oral exposure to zinc oxide nanoparticles. Mutat Res. 2012; 745:84-91.

24. Vandebriel RJ, De Jong WH. A review of mammalian toxicity of ZnO nanoparticles. Nanotechnol Sci Appl. 2012; 5:61-71.

25. Chung HE, Yu J, Baek M, Lee JA, Kim MS, Kim SH, et al. Toxicokinetics of zinc oxide nanoparticles in rats. J Phys Conf Ser. 2013; 429: 1-7.

26. Al-Rasheed NM, Faddah LM, Mohamed AM, Abdel Baky NA, Mohammad RA. Potential impact of quercetin and idebenone against immuno-inflammatory and oxiditive renal damage induced in rats by titanium dioxide nanoparticles toxicity. J Oleo Sci. 2013; 62:961-71.

27. Xia T, Kovochich M, Liong M, Mädler L, Gilbert B, Shi H, et al. Comparison of the mechanism of toxicity of zinc oxide and cerium oxide nanoparticles based on dissolution and oxidative stress properties. ACS Nano. 2008; 2:2121-34.

28. Müller KH, Kulkarni J, Motskin M, Goode A, Winship P, Skepper JN, et al. pH-dependent toxicity of high aspect ratio $\mathrm{ZnO}$ nanowires in macrophages due to intracellular dissolution. ACS Nano. 2010; 4:6767-79.

29. Kao YY, Chen YC, Cheng TJ, Chiung YM, Liu PS. Zinc oxide nanoparticles interfere with zinc ion homeostasis to cause cytotoxicity. Toxicol Sci. 2012; 125:462-72.

30. Chang YN, Zhang M, Xia L, Zhang J, Xing G. The toxic effects and mechanisms of $\mathrm{CuO}$ and $\mathrm{ZnO}$ nanoparticles. Materials. 2012; 5:2850-71.

31. Thakur M, Gupta H, Singh D, Mohanty IR, Maheswari U, Vanage G, et al. Histopathological and ultra-structural effects of nanoparticles on rat testis following 90 days (Chronic study) of repeated oral administration. J Nanobiotechnol. 2014; 12:42

32. Iavicoli I, Fontana L, Leso V, Bergamaschi A. The effects of nanomaterials as endocrine disruptors. Int $\mathrm{J}$ Mol Sci. 2013; 14:16732-801.

33. Kumar V, Abbas AK, Fausto N, Aster JC. Robbins and Cotran pathologic basis of disease. New York: Elsevier Health Sciences; 2014, 1-30.

34. Boots AW, Haenen GR, Bast A. Health effects of quercetin: from antioxidant to nutraceutical. Eur J Pharmacol. 2008; 585:325-37.

35. Muthukumaran S, Sudheer AR, Menon VP, Nalini N. Protective effect of quercetin on nicotine-induced prooxidant and antioxidant imbalance and DNA damage in Wistar rats. Toxicology. 2008; 243:207-15.

36. Joskova M, Franova S, Sadlonova V. Acute bronchodilator effect of quercetin in experimental allergic asthma. Bratisl Lek Listy. 2011; 112:9-12.

37. Prabu SM, Muthumani M, Shagirtha K. Quercetin potentially attenuates cadmium induced oxidative stress mediated cardiotoxicity and dyslipidemia in rats. Eur Rev Med Pharmacol Sci. 2013; 17:582-95.

38. Prince PS, Sathya B. Pretreatment with quercetin ameliorates lipids, lipoproteins and marker enzymes of lipid metabolism in isoproterenol treated cardiotoxic male Wistar rats. Eur J Pharmacol. 2010; 635:142-8.
39. Azevedo MI, Pereira AF, Nogueira RB, Rolim FE, Brito GA, Wong DVT, et al. The antioxidant effects of the flavonoids rutin and quercetin inhibit oxaliplatin-induced chronic painful peripheral neuropathy. Mol Pain. 2013; 9:53.

40. Dong YS, Wang JL, Feng DY, Qin HZ, Wen H, Yin ZM, et al. Protective effect of quercetin against oxidative stress and brain edema in an experimental rat model of subarachnoid hemorrhage. Int J Med Sci. 2014; 11:282 